\title{
Critical Conflict Resolution, Systemic Consciousness and Systemic Contractions
}

\section{Michael D. English and Derek Sweetman}

\begin{abstract}
This paper offers an introduction to Critical Conflict Resolution, a form of conflict resolution practice that addresses larger, systemic concerns while also focusing on the conflicts produced by systemic contradictions. It describes two forms of practice for these conflicts, emergent and evolutionary, as well as identifying the need to develop systemic consciousness in both practitioners and parties in order to produce real change. It provides suggestions for practitioners and conflict scholars as they engage with this developing area of practice.
\end{abstract}

\section{Keywords}

Conflict Resolution, Criticism, critical evaluation, systemic contractions, systemic consciousness

\section{Introduction}

The Critical Conflict Resolution project began as an effort to understand the role conflict resolution could play in conflicts that we identified as systemic. Our work arose, initially, out of a desire to apply the tools of conflict resolution to the system-challenging conflicts at the time: The Arab Spring and the Occupy movement in the United States. ${ }^{\mathrm{i}}$ These events served as a vehicle to help us generate a schema and vocabulary to describe situations that required something more than traditional third party intervention. Today, one of the most obvious cases of a systemic conflict in the United States involves law enforcement and the African-American community, represented by the Black Lives Matter movement. The cessation of hostilities between activists and the police is a laudable goal, as is the "resolution" of the immediate conflict; but in this conflict, bringing two parties to the table does not appear to have a long-lasting impact on how the police do their job or how activists relate to both perceived and real injustices perpetrated by law enforcement. This situation is true for those struggling not only in cities like Baltimore and Ferguson, but also in Cairo and Istanbul.

This article will present an overview of the model of Critical Conflict Resolution (CCR). ${ }^{\text {ii }}$ While CCR employs and builds from concepts within peace and conflict studies, it also integrates insights from the critical philosophical tradition and therefore uses terminology that might be new (and somewhat awkward) to practitioners unfamiliar with the critical tradition. Our goal is to help peace and conflict 
studies reengage with this tradition and its knowledge, which for the better part of our field's history was mystified by Cold War political posturing, in order to address conflicts that are not otherwise amenable to traditional third-party intervention. It is important to note that our usage of the term critical denotes something more substantial than what is typically described as critical thinking. As will be discussed later, the critical tradition offers a way of appreciating the importance of historical developments on social conflicts in a manner that meshes both the personal and the material. Another way of saying this might be to argue that we are attempting to root a specialized version of critical thinking in the normative, social justice orientation of peace and conflict studies.

Critical Conflict Resolution can assist practitioners and analysts in cultivating an awareness of systemic factors or what we refer to as developing a systemic consciousness. Given the exceedingly complex contemporary social struggles in which race, gender, and economic injustice sit at the forefront, we must develop additional tools for analysing and intervening in situations where traditional third party practice alone is insufficient.

Critical Conflict Resolution postulates that in cases of systemic conflict, conflict occurs on at two levels, the manifest level and the system level. A conflict is manifest when it is visible and the parties involved recognize themselves to be in a situation that cannot be resolved through a simple negotiation or termination of relationship.iii The history of conflict resolution and alternative dispute resolution (ADR) is premised on the ability of third parties to intervene at this level, working to reduce hostilities, clarify problems, and in the best cases, empower the parties to generate mutually agreeable solutions. Given that many social conflicts are not also systemic conflicts, these processes generally do the trick and speak decidedly about the ability of people to learn and use communicative practices to resolve their differences. However, in cases of systemic conflict, we are confronted with conflicts that resist resolution or, in some cases, where the same type of conflict recurs between other parties in other locations. We term these conflicts reproduced conflicts. Settlements in these situations are possible, but often temporary and subject to repeated breakdowns. This failure is rarely due to character flaws or the bad faith of individual actors; rather, failure is a result of structural and cultural factors that influence both the conflict and the parties involved. We identify these factors as operating at the system level because they structure the world in which the parties (and the intervenors) live; they provide us with both the language and meaning frameworks we use to process our experiences, as well as normalize the operations of power used to reproduce the rules governing a given system.

We are rarely conscious of the influence of systemic factors in our daily lives, and typically even less so when engaged in our practice. There may be perfectly good reasons for reaching a negotiated settlement, but in systemic conflicts a negotiated settlement will not prevent a reoccurrence of the conflict. Only by changing the underlying system dynamics can the contradiction generating the antagonism be transformed and, hopefully, moved down a path toward resolution, which should reduce or eliminate the reproduced conflicts created by this contradiction. Systemic conflict cannot be tackled by focusing only on the few bad apples or trimming the rot at thetop. 


\section{Seeing the Contradiction: The Case of Ferguson}

Before going any further, we want to present an example to help illustrate the significance between recognizing conflict as manifest and recognizing conflict as systemic. The shooting death of Michael Brown in 2014 by Ferguson, Missouri police officer Darren Wilson set off a wave of protests across the United States. Brown was one of several African American men shot and killed by police officers that year. The details leading up to the incident, as well as those of the actual killing of Brown are contested.

At the manifest level, the community of Ferguson demanded Brown's death be investigated as part of a history of mistreatment of African Americans by the police department, and the officer involved charged with a crime. The Ferguson Police, both in defence of Officer Wilson and in opposition to what it felt was an inaccurate depiction of its service to the community, portrayed Brown as a dangerous thug and accused those involved in the protests as being manipulated by outside agitators. A typical analysis conducted by a third party would likely conclude that the protestors and the police are the two major stakeholder groups, and that the best course of action in this conflict would be to bring leaders from the police and activists together for some kind of facilitated dialogue or problem-solving process. Other stakeholders from local government and organizations might also be included. The work of the mediator would likely focus on identifying a mutually agreeable solution to the problem between police and protestors. But what in this case is the actual problem? And will an agreement between police and protestors actually resolve it?

Here, of course, is where our concern with issues of power and justice make it difficult to accept that third party practice focused on improving communication can provide a path to resolution. For the police, the problem is often the act of protest itself, which is viewed both as destructive and a challenge to the police's mandate to maintain social order within a specific geographic location. From this view, the killing of Michael Brown is tragic, but Brown's failure to comply with Officer Wilson instigated the situation and as such, the community's response is unjustified. Respect for police authority is the foremost solution to this problem. On the other side, community members, and not just those engaged in the protests, note that the police department has a history of abusing its power and acting against the well-being of the community. The killing of Michael Brown was the last straw, and the status quo is no longer worth returning to if the law does not prosecute those charged with upholding it for violating their duty. Respect for the community is the primary solution to this problem, and this cannot happen without replacing police leadership and holding officers accountable. Both solutions are framed as zero-sum propositions and intentionally so, to demonstrate how unsatisfactory a negotiated settlement is likely to be in such asituation.

Outside investigations later vindicated the community's perception of the police, while at the same time, these same investigations found little evidence of wrongdoing to prosecute Officer Wilson for Brown's death. While tensions might exist between activists and the police, neither activists nor the police can resolve the contradiction that rests at the centre of this conflict, which extends far beyond the series of events that led to Brown's death and Wilson's dismissal. Developing an awareness of the systemic level 
and systemic factors allows practitioners to see beyond the immediate situation, and to historicize the case before them. Brown's death served as a catalyst for a collective series of actions in protest of police shootings, yet the conflict is ultimately not about Michael Brown or the Ferguson Police Department. It is about the treatment of African-American and low-income communities by police, the state agency often responsible for providing services in areas that face extreme levels of poverty and unemployment. The police have no way of changing these economic conditions. Improving relations between the police and the communities they serve is a laudable goal, but one that offers little in terms of preventing a reoccurrence of the conflict in Ferguson or in other communities facing similar conditions.

\section{Necessary Concepts}

The ability of intervenors to recognize systemic factors in such conflicts is built upon two bedrock concepts, systemic contradiction and systemic consciousness. While inspired by Marxist analysis that sees economic contradictions as the driving force of history, this conception of systemic contradiction is more concerned with form than content. ${ }^{\text {iv }}$ In any complex system, there are elements that are in tension with one another where that tension cannot, in a real sense, be "resolved" in a way that keeps the benefits of the separate elements and simultaneously, removes the negative consequences of the interactions. The ability to resolve tension in a system allows us to differentiate between systemic problems, which can be addressed by modifying individual elements, and systemic contradictions, which cannot be resolved within the context of the existing system. The contradictions may be economic, but they may also be cultural, structural, or even exist in a currently-unobserved form. Systemic contradictions become evident to us in the world through the recognition of reproduced conflicts. We recognize that a system with serious contradictions can persist for a very long time, and that the presence of contradictions does not mean a system is weak or failing. All large systems will include some contradictions and, as a result, one of our roles is to identify and transform destructive contradictions.

We argue that these systemic contradictions will create conflict that repeats throughout the system. It is important to realize that while these reproduced conflicts share a common "root cause" (the contradiction itself), this does not mean two conflicts must be identical to be classified as reproduced. Similarly, not all conflicts that appear significantly similar are related in this way. Identifying true reproduced conflicts is one of the key challenges of CCR, and one that needs additional work.

This allows us to recognize that Ferguson is a case of reproduced conflict, where, the systemic contradiction is created by a mix of economic and historical factors. One factor that encourages this conclusion is the demographic makeup of the community. Any intervenor must be curious about the geographic dispersal of people, especially when the conflict reveals disparities along racial and economic lines. The predominantly African American composition of Ferguson clashed quite visibly on national television with what was perceived to be the predominantly white composition of the police department, state and local officials. Race is therefore a factor, but so also is class. It comes as little surprise that news reports focused on Ferguson's poverty as soon clashes broke out, revealing statistics that one in four 
persons in the community lived in poverty. ${ }^{\mathrm{v}}$ While it is always tempting to blame one of these factors as the sole cause, such simplistic analysis misses the dynamic relationship these factors have structured between the police and the community.

The second necessary concept is systemic consciousness, which we derive from the work of Paolo Freire, who describes conscientizaçāo (conscientization) as "the deepening of the attitude of awareness characteristic of all emergence" (1993, p.109). For Freire, this awareness arises out of an individual's ability to recognize that they are "in a situation," meaning that they live within a system of forces and meanings that shape their opportunities and outcomes. This awareness is created through a process of critical thinking that results in the situation "ceas[ing] to present itself as a dense, enveloping reality or a tormenting blind alley," from which the individual can "perceive it as an objective-problematic situation" (ibid, p.109). Freire recognizes that "intervention" is impossible without "emergence" from the situation through systemic consciousness.

For intervenors, the development of a personal systemic consciousness is what allows third parties to enter situations like the one in Ferguson with the foresight that the work to be done is something more than a negotiated settlement between the parties, even though that may be the starting point. Here again, we move beyond just knowing the history of the immediate parties involved, but the history of relations between groups, communities, and organizations. Where did the relationship pattern emerge and what continues to reproduce the economic and/or social disparities that enforce the relationship? We also become keenly aware of how groups recognize shared grievances in events occurring outside their geographic boundaries, and how the ability to access information on demand replaces old notions that the parties to the conflict are those immediately present. Now, actors from across the globe can shape and influence how parties understand even the most local of conflicts and the strategies they use to contest. The shooting of Michael Brown must be contextualized alongside a variety of similar cases that polarized communities, including other recent deaths such as Tamir Rice and Freddie Grey, but also older incidents such as the shootings of Amadou Diallo and Timothy Thomas. Conflict between the police and African-American communities span the whole of U.S. history, and yet, there is a temptation when such events arise every decade or so to assume, rather paradoxically, that this conflict is either new or already resolved.

From these two concepts, it is possible to map out a new model of conflict resolution that intends to address systemic conflicts.

\section{Outline of the CCR Approach}

The Critical Conflict Resolution approach conceives of systemic conflict and its intervention as a process that can be divided into four parts: manifestation, emergent practice, evolutionary practice and critical evaluation. It is imperative to remember that the impetus behind the critical approach is to address the contradiction, not simply the manifested, reproduced conflict. 


\section{Manifestation}

The first step in the CCR approach is for the intervenor to evaluate the manifestation of the conflict, and to distinguish whether the conflict is systemic or localized. Contradictions are rarely visible to the eye, yet they materialize in the form of conflicts that can be observed in the social world. To make such an evaluation, the intervenor analyses the situation for the presence of a contradiction or contradictions that might be feeding the antagonism between the parties. For instance, community outrage over injustices rarely erupt as the result of one death, even if media coverage and official explanations simplify such events by reporting a causal linkage between the two. Michael Brown's death in Ferguson and Mohamed Bouazizi's self- immolation in Tunisia, which helped launch the Arab Spring, speak to larger structural antagonisms, which often play out in relations between police forces and populations.

Recognizing the tools for this analysis are still underdeveloped, we can provide three initial suggestions related to distinguishing between systemic and localized conflicts. ${ }^{\mathrm{vi}}$ The first of these is simply to recognize repetition. If the "same" conflict arises repeatedly either between the parties or in different locations under similar circumstances, this is a good indication that there is an underlying systemic contradiction contributing to the manifestation of this conflict. This was the primary insight of Black Lives Matter, helping others see fatal interactions between police and unarmed African-American men as symptomatic instead of isolated episodes.

The second suggestion is to closely examine hard-to-resolve conflicts. All practitioners have had the experience of intervening in a conflict where they feel the solution seems obvious, and yet, one (or more) of the parties refuses to accept, or even consider it. This additional resistance might reveal the presence of systemic factors, particularly when dynamics such as race, class, and gender are assumed inconsequential to achieving an agreement.

A third suggestion is to look for repeated sub-optimal outcomes in conflict resolution. One of the difficulties in identifying contradictions is that reproduced conflicts can appear amenable to negotiated settlement. This is in part because the system has already influenced what the parties see as acceptable (or even possible) outcomes. This narrowing of possibility pressures parties toward immediate solutions, and often prevents parties from pushing the matter far enough to reveal that the system itself is implicated. Since most conflict resolution approaches value party autonomy and agency over optimal certainty, practitioners often have a good sense of when parties may have left gains "on the table." While settlements may satisfy a need for closure or material compensation, they are rarely comprehensive. This distance between accepted and optimal outcomes may point to systemic conflicts.

After a conflict has been recognized as systemic, intervention takes place in three separate parts of CCR: emergent practice, evolutionary practice, and critical evaluation. 


\section{Emergent Practice}

"Emergent practice" is our term for intervention targeted at the manifest level, as opposed to intervention focusing on the contradictions at the system level. Practitioners at this level are the "first responders" of CCR. Primarily, emergent practice occurs at the interpersonal and community levels, but it is not limited to these. On its face, emergent practice looks similar to traditional conflict resolution practice, with one important difference.

It would be unethical to allow people to suffer in conflicts when we could otherwise assist with the tools of conflict resolution, even if such a resolution would not resolve the underlying contradiction that is reproduced in the conflict. However, simply mitigating the damage of the contradiction will allow the contradiction to persist. Therefore, we must add systemic consciousness to our practice to promote this resolution.

Systemic consciousness applies to both the practitioner and the parties in the conflict. In traditional conflict resolution, we are not only helping parties resolve their conflicts, but also trying to teach them to use similar tools to resolve conflicts in their future. This pedagogical function of conflict resolution is seldom recognized, but should be acknowledged as a crucial component of our work. CCR sees this act of teaching as a vital tool for building systemic consciousness within the parties. As we teach parties skills of conflict resolution during our practice, we need to teach the skills of systemic consciousness. Clearly, this also entails cultivating systemic consciousness within themselves that is attentive to the situation of the parties and the situation in which the practitioner finds herself, which makes this a more complex activity than what is generally described as reflective practice. ${ }^{\text {vii }}$

Four basic principles guide practice at the manifest level. First, we should simply help. Most (if not all) systemic contradictions cannot be resolved in a single case, but this does not mean we should allow the reproduced conflicts to continue. Following Schoeny and Warfield (2000), we recognize the moral dilemma with pneumatic models of social change that claim enough suffering will lead to change. One of the strong ethical obligations we have as practitioners is to act when we expect our assistance will make a difference. Hopefully, through developing systemic consciousness, we will learn to separate interventions that reinforce contradiction from those that resist or at least do not assist it.

Second, we must seek connections between conflicts. The bureaucratized nature of much conflict resolution work encourages practitioners to treat each conflict as a separate "case," to be completed and filed away. In some situations, ADR programs actively require this kind of thinking, in part to prevent breaches in client confidentiality. However, to see reproduced conflicts, we must be able to investigate across these "case" boundaries. Only critical reflection and review can help with this.

Third, the people most effected by a contradiction are likely in the best position to help us understand it. First responders are also field researchers. The raw data that we use to generate our analysis comes from the parties in conflict and is dependent, to a large extent, on their interpretation of their experience. Practitioners at the emergent level should appreciate the unique research aspect of their work, and seek to engage parties when possible as co- constructors of knowledge. 
Finally, no one is a "solo practitioner." CCR is collective work to resolve collective problems, practiced through a community of practitioners and scholars. To participate in this community, you must share your knowledge and experiences with fellow practitioners, researchers, and the broader public. This act of sharing moves us from emergent practice into evolutionarypractice.

\section{Evolutionary Practice}

At first, what we call "evolutionary practice" may not often seem like conflict practice, at least in the traditional sense. However, the concept of mediation itself provides a bridge between traditional and evolutionary approaches. When conflict resolution scholars and practitioners speak of mediation, they are referring to a host of processes that involve a third party inserting herself between parties in a conflict to assist in the conflict's resolution. Yet this interpretation emphasizes only one aspect of mediation. Raymond Williams writes that, instead, there are two important features of "mediation." Looking back to Chaucer, Williams recognizes that "mediation" functions both to represent "interceding between adversaries, with a strong sense of reconciling them" and "a means of transmission - or agency as a medium" (1985, p.204). viii While conflict resolution has focused extensively on the first, our work requires that we also develop and deploy mediation in this second sense, which has been developed through Marxist analysis into "one of the essential processes not only of consciousness, but of ideology" (ibid, p.206).

Evolutionary practice is intervention made into the mediated world of consciousness and ideology. Since there is no way to "speak" to the system itself, there is no way to mediate its contradictions in the first sense. We must therefore promote action through interventions that seek to reform, reconstitute, or replace the existing system to resolve the contradictions. Evolutionary activity aims to demystify that which obscures the true contradictory reality of a given system. Pierre Bourdieu, speaking in the context of Neoliberalism, noted that a system has "the means of making itself true and empirically verifiable" (1998, np). As an intervention, such practice confronts the rules guiding social interactions within the system and contests discourses that support unjust exercises of power.

There are existing forms of conflict resolution practice that operate in an evolutionary fashion, from narrative intervention (Cobb, 2013) to media engagement (Galtung \& Fischer, 2013) to peace and/or critical education (hooks, 1994; Giroux, 2008). Other forms of evolutionary practice are less likely to be considered traditional conflict resolution. This includes interventions in the political system that are specifically not consensus-driven, such as activism, as well as activities, particularly efforts in the realm of music, art, film, and literature, undertaken to interfere with the system's ability to decide what is "true." Often, these interventions take the form of satire that undermines truth claims, a prime example of which is the genre of war satires epitomized by Joseph Heller's Catch-22. Another example, Pussy Riot's "I Can't Breathe," combines political activism and art in an effort to reach audiences that might otherwise be oblivious to injustices that happen outside of their own local context. ${ }^{\text {ix }}$

To summarise, there are four basic principles that support evolutionary or, more specifically, 
within the individuals within the system. This sounds daunting, but it is simply a call for more critical reflection among the parties to the system.

Next, we recognize that systemic contradictions do not naturally resolve in the Hegelian sense, or inevitably lead to systemic revolution, in the simplistic Marxist sense. Instead, the process is long and difficult, thus "evolutionary" instead of "revolutionary."

Additionally, addressing these contradictions on the systemic level has the potential to produce additional reproduced conflicts, at least in the short term. Which is closely related to the next insight; interventions upon the system, if in any way effective, will change the nature of the system. We must constantly re-evaluate the system and look for variations in reproduced conflicts. Resolving systemic contradictions is a reflexive process, which means that neither our analysis, nor our interventions can be cookiecutter.

Finally, and unlike the manifest level, there are many targets and sites for intervention at the system level. Practitioners are not restricted to working only with the parties; they can expand their vision work toward changing the conditions in which the conflict takes place. For example, evolutionary practitioners might focus on helping individuals see the damage caused by the systemic contradictions and/or see how the contradiction leads to reproduced conflict. They could also provide the language, metaphors, or analogies that allow us to speak of issues previously unspeakable, a task often left to the humanities, whether art in the sense of Picasso's masterpiece Guernica or philosophy, when seen through Gilles Deleuze and Felix Guittari's lens as an engine of concept-creation (1994,p.3).

Both emergent and evolutionary practice must be supported by scholarly work, which in this case we call critical evaluation.

\section{Critical Evaluation}

Scholarship and research remain an essential third form of practice in CCR. Critical evaluation stresses the interdisciplinary nature of peace and conflict studies, but seeks to encourage the creation of more scholarship directed specifically at systemic conflicts and systemic interventions. In the first instance, critical evaluation reflects the traditional aims of academic production, yet places the emphasis on researchers to, when possible, address both the manifest and systemic levels. Conflict experts tend towards being area specialists. While that depth of knowledge is important, it too often becomes an excuse for viewing their conflict as unique, rather than an opportunity to make connections with other cases, or investigate the role of global factors external to the immediate situation.

In the second instance, critical evaluation also stresses the need for more research on designing and evaluating systemic interventions. Researchers working on these issues must do a better job of engaging both emergent practitioners and parties to explore what types of interventions and practices are best suited to doing the most immediate good while also addressing the systemic contradictions.

No academic discipline or field has a monopoly on truth about systems and conflict, which means there are endless possibilities for collaboration across departments and organizations. 
Communication is free and it is becoming increasingly easier to speak with people all over the world. Researchers must stretch beyond their departments and especially beyond academia, to engage those closest to manifest conflicts.

\section{Implications of CCR for Practitioners and Scholars}

In closing, we would like to briefly outline a few of the implications of CCR for practitioners and scholars in the field of peace and conflict studies. First, it is no longer enough to speak simply of reflective practice. Developing a systemic consciousness is the next evolutionary step for the field, and such an activity requires that we apply systemic awareness not only to our interventions, but also our work as researchers and teachers. Second, we must place more emphasis on distinguishing systemic conflicts from localized conflicts.

Connections between the local and the global are interlinked today more than at any other period in history. There is a pressing need to recognize how structural factors have helped structure the relationship between antagonistic parties. Third, there is a need for multi-level listening. Listening to the parties is always a crucial part of interventions and research, but we must also learn to hear the context, which remains unspoken by the parties. This can be done in part by proper background research, but it also requires us to use the tools of discourse and narrative analysis to deconstruct the rules guiding the parties' interactions and to search for meaning in silences and topics that remain unaddressed. Fourth, we must participate in dialogue across both professional and academic divides. There may not be final answers to our questions, but that should not prevent us from trying.

Borrowing from Marx, we can say that the point of conflict resolution is to change the world, not comprehensively document it. This cannot happen if scholars refuse to engage with practitioners, or if practitioners dismiss scholarship as disconnected from the realm of the practical. The development of CCR will be a collaborative process and we encourage both those new to the field and those already committed to join us its elaboration. 


\section{References}

Bourdieu, P. (1998) "The Essence of Neoliberalism". Le Monde Diplomatique, December, http://mondediplo.com/1998/12/08bourdieu, np. Jeremy J. Shapiro, translator.

Cobb, S. (2013) Speaking of Violence: The Politics and Poetics of Narrative Dynamics in Conflict Resolution. New York, NY: Oxford University Press.

Deleuze, G. and F.Guattari (1994) What is Philosophy? London: Verso Books. Freire, P. (1993) Pedagogy of the Oppressed. New York, NY: Continuum.

Galtung, J. and D. Fischer (2013) "High Road, Low Road: Charting the Course for Peace Journalism" in "Johan Galtung: Pioneer of Peace Research", SpringerBriefs on Pioneers in Science and Practice 5. Berlin, GER: Springer: 95- 102, doi:10.1007/978-3-642-32481-9_8.

Giroux, H. (2008) Pedagogy and the Politics of Hope: Theory, Culture, and Schooling. Boulder, CO: Westview Press.

hooks, b. (1994) Teaching to Transgress: Education as the Practice of Freedom

New York, NY: Routledge.

Schoeny, M., W.Warfield (2000) Reconnecting Systems Maintenance with Social Justice: A Critical Role for Conflict Resolution. Negotiation Journal 16 (3): 253- 68, doi:10.1023/A:1007556129999.

Williams, R. (1985) Keywords: A Vocabulary of Culture and Society, Rev. ed. New York, NY: Oxford University Press.

\section{Notes}

${ }^{i}$ Aspects of this article were presented at the 2013 and 2016 Association for Conflict Resolution Annual Conferences as "“"Critical Conflict Resolution: Practice in the New Normal” and "Critical Work in Communities: Transforming Systemic Violence." An early formulation of our thinking was published in English, M.D. and D. Sweetman, "Critical Conflict Resolution: Notes on Its Development and Key Concepts," Unrest Magazine, October 2013, https://unrestmagazine.com/2016/10/03/criticalconflict-resolution/. Readers of both articles will note similarity, but also differences that we hope clarify areas of prior confusion and expand the applicability of the work.

ii Toren Hansen first used the term "critical conflict resolution" in a 2008 article of the same name. Readers of both articles will notice a significant diversion from Hansen's usage, even if we do share a similar orientation.

iii This definition finds its root in Kriesberg's definition of a social conflict. See Kriesberg, L. 1982. "Social Conflict Theories and Conflict Resolution”. Peace \& Change 8, no. 2-3: pp. 3-17.

Doi:10.1111/j.1468-0130. 1982.tb00644. x.

iv The role of contradiction in Marxist theory has been discussed extensively. See Althusser, L. 1967. "Contradiction and Overdetermination". New Left Review, no. 41: 15-35; Williams, R. 1973 "Base and 
Superstructure in Marxist Cultural Theory2. New Left Review, no. 82: pp.3-16; Giddens, A. 1979. Central Problems in Social Theory: Action, Structure, and Contradiction in Social Analysis. Berkeley, CA: University of California Press.

${ }^{\mathrm{v}}$ See for instance http://www.cbsnews.com/news/hit-by-poverty-ferguson-reflects-the-new- suburbs/

${ }^{v i}$ Helpfully, critical disciplines such as Cultural Studies have begun to develop tools for seeing beyond manifestations and behaviors to the contradictions behind them. See for instance Hebdige, D. Subculture: The Meaning of Style, New Accents (New York, NY: Routledge, 1991).

vii See Warfield, W. and Cheldelin, S. "Reflections on Reflective Practice," in From Conflict Resolution to Social Justice: The Work and Legacy of Wallace Warfield, ed. Pfund, A. (New York, NY: Bloomsbury Publishing, 2013), pp.147-62.

viii Williams identifies a third meaning of mediation, "division or halving," but concludes this is "now obsolete."

ix Pussy Riot's work was published on the free streaming website Youtube in response to the death of Eric Garner. https://www.youtube.com/watch?v=dXctA2BqF9A

\section{Biographies}

Dr. Michael D. English is an adjunct lecturer at the School for Conflict Analysis and Resolution at George Mason University.

Derek Sweetman is a PhD candidate at the School for Conflict Analysis and Resolution at George Mason University and the Dispute Resolution Director for the Better Business Bureau of Metropolitan Washington, DC and Eastern PA. 